\title{
Chronic idiopathic polyneuropathy presenting in middle or old age: a clinical and electrophysiological study of 75 patients
}

\author{
Nicolette C Notermans, John H J Wokke, Hessel Franssen, Yolanda van der Graaf, \\ Marinus Vermeulen, Leonard $H$ van den Berg, Peter R Bär, Frans G I Jennekens
}

\begin{abstract}
The clinical and electrophysiological features were prospectively studied of 75 patients (46 men and 29 women) with chronic polyneuropathy presenting in middle or old age in whom a diagnosis could not be made even after extensive evaluation and a follow up of six months. The mean age at the onset of symptoms was 56.5 years. The clinical features of chronic idiopathic polyneuropathy are heterogeneous. On clinical grounds 44 patients had a sensorimotor, 29 patients a sensory, and two patients a motor polyneuropathy. The overall clinical course in chronic idiopathic polyneuropathy was slowly progressive. None of the patients became severely disabled. Electrophysiological and nerve biopsy studies were compatible with an axonal polyneuropathy. Antibodies against myelin associated glycoprotein, gangliosides, and sulphatides were assessed in 70 patients and found to be negative.
\end{abstract}

(F Neurol Neurosurg Psychiatry 1993;56:1066-1071)

Although chronic polyneuropathy presenting in middle or old age is often secondary to systemic diseases, a group of neuropathies remains in which no diagnosis can be made. ${ }^{1-9}$ Studies performed in the early 1950 s described a high (50-70\%) percentage of idiopathic neuropathies. ${ }^{1-2}$ Recent series report percentages of approximately $10-15 \% .^{368}$ This marked decline results from the recognition of new entities such as the chronic inflammatory demyelinating polyneuropathy (CIDP), ${ }^{10}$ neuropathies associated with monoclonal gammopathy, ${ }^{11}$ and from improved classification systems as in hereditary neuropathies. ${ }^{5}$ Nevertheless, a group of patients remains in which a diagnosis cannot be made.

To date, there are no prospective clinical studies on this subject. We studied the clinical and electrophysiological features of patients with chronic symmetrical polyneuropathy presenting in middle or old age in whom after extensive evaluation no diagnosis could be made. In order to determine whether immunological processes play a pathogenic role in chronic idiopathic polyneuropathy we assessed whether antibodies against myelin associated glycoprotein, gangliosides, and sulphatides are demonstrable.

\section{Methods}

Between 1987 and 1991 we studied 75 patients with a polyneuropathy in whom no diagnosis could be made after extensive evaluation. Of these patients, 53 were directly referred by other neurologists to the department of neuromuscular diseases in Utrecht. From 1987 to 1991 approximately 500 patients with polyneuropathy were diagnosed in our department. Consequently, in our group of neuropathies $10 \%$ were idiopathic. The remaining 22 patients were referred to us after diagnosis in other University Hospitals (Rotterdam, Nijmegen, Amsterdam), so the total number from which they were drawn are not known. All patients were repeatedly examined by the same neurologist (NCN). A patient was eli-gible if: (1) neurological examination showed symmetrical signs of sensory or motor impairment of the limbs with a distal distribution; (2) the polyneuropathy had a slow onset and developed gradually in months rather than days or weeks; (3) electrophysiological investigations were compatible with a peripheral neuropathy; (4) the first symptoms of the neuropathy appeared between the age of 45 and 70 years. The limit of 45 years was chosen because the majority of inherited polyneuropathies presents at a younger age. ${ }^{12}$ The limit of 70 years was chosen to exclude any possible effect caused by the normal ageing process of the nervous system $^{13}$; (5) all laboratory tests were within normal limits, except for serum antibodies (see Laboratory section).

The following patients were excluded: (1) patients in whom a definite diagnosis could be made by clinical, laboratory or histological examinations; (2) patients with an elevated CSF protein level $(>1 \mathrm{~g} / \mathrm{l})$ in combination with electrophysiological signs of demyelination, to prevent the inclusion of patients with a CIDP ${ }^{10}$; (3) all patients with a history of any disease which could be associated with a neuropathy (for example, malignancy, intestinal surgery, thyroid disease).

\section{PATIENT EVALUATION}

After scrutinising all inclusion criteria the neurological interview and examination were carried out in a standardised fashion. This included an extensive interview to determine the nature and distribution of motor, sensory, and autonomic symptoms (blurred vision, orthostatic hypotension, ability to sweat, bowel and cardiac dysfunction, impotence, sphincter incontinence), the progression of the disease, the degree of physical disability, 
the concurrence of other diseases or possible intoxications (medication, alcohol, occupational and environmental toxic agents). A detailed kinship history was taken to minimise the chance of including patients with a hereditary polyneuropathy; when there was any doubt, next of kin suspected of having a neuropathy were neurologically examined. ${ }^{5}$

Six muscles in both arms (deltoid, biceps brachii, triceps brachii, finger extensors, finger flexors, and interosseus) and six muscles in both legs (iliopsoas, quadriceps, hamstrings, anterior tibial, gastrocnemius, and peroneus) were tested, using the MRC grading system. Summation of the proximal or distal limb score could each lead to a maximum motor score of 30 . Deep tendon reflexes in both arms (biceps jerk, triceps jerk) and in both legs (knee jerk, Achilles jerk) were tested and graded as follows: normal $=2, \quad$ diminished $=1, \quad$ absent $=0$. Summation of the reflex scores of both sides could lead to the maximum score of 4 for each reflex. The following sensory modalities were examined: touch, pinprick, vibration, and joint position sense. The sensory system was graded as follows: touch and pinprick sense; normal $=4$, distal to wrist/ankle abnor$\mathrm{mal}=3$, distal half forearm/leg abnormal $=2$, distal to elbow/knee abnormal $=1$, distal to axilla/groin abnormal $=0$. Vibration sense: tuning fork perception $(128 \mathrm{~Hz})$ on: middle finger/hallux $=4$, ulnar styloid/medial malleolus $=3$, elbow $/$ knee $=2$, clavicula $/$ crista $=1$, no perception $=0$. Summation of each of these sensory modalities could lead to a maximum score of 16 . Joint position sense of middle finger/hallux: normal $=2$, diminished $=1$, absent $=0$. Summation could lead to a maximum score of 8 . In addition all patients were assessed with the modified Rankin scale. ${ }^{14}$

\section{LABORATORY}

The following laboratory investigations were performed in every patient and had to be normal: haemoglobin, haematocrit, leucocytes, platelets, erythrocyte sedimentation rate, serum glucose, renal function and electrolytes, liver enzymes, serum calcium and phosphorus, creatine kinase, serum protein, transketolase, vitamin B12, folic acid, thyroid function, serum agargel and immunoelectrophoresis, antinuclear antibodies, cryoglobulins, rheumatoid factors. All patients had a routine chest $x$ ray and a total body bone scan. In addition, CSF was obtained in almost all of the patients. The presence of serum antibodies against myelin associated glycoprotein (MAG) was investigated by thin layer chromatography, using the glycolipid SGPG (kindly provided by $\mathrm{Dr} \mathrm{N}$ Latov, Columbia University, New York, USA). ${ }^{15}$ Sera were tested for antibodies against GM1 gangliosides $^{16}$ and against sulphatides (ELISA, measured by $\mathrm{Dr} \mathrm{N}$ Latov). ${ }^{17}$ Whenever there was any suspicion on clinical or laboratory grounds of an inflammatory or infiltrating disorder (vasculitis, amyloidosis, sarcoidosis, and inflammatory demyelinating neuropathy), inherited storage disorder and abnormality of myelination, a sural nerve biopsy was performed. ${ }^{18-20}$ In all patients with a slightly elevated CSF protein $(0.45-1.0 \mathrm{~g} / \mathrm{l})$ a biopsy was also taken and only those patients whose biopsy showed no signs of inflammation or infiltration were entered into the study. ${ }^{21}$

\section{ELECTROPHYSIOLOGICAL ASSESSMENT}

Electrophysiological investigations according to the procedure described below were carried out in 60 patients in order to confirm and classify the peripheral neuropathy. The first dorsal interosseus and tibial anterior muscles were examined using concentric needle investigation. Nerve conduction studies were performed with surface electrodes using standard techniques. ${ }^{22}$ We investigated the ulnar nerve (motor and sensory) in one arm, the tibial nerve (motor) and the sural nerve in one leg, and the H-reflex of the soleus muscle in the opposite leg. The following variables were measured: distal motor latency (DML), motor and sensory conduction velocity (CV), the compound muscle action potential (CMAP) amplitude (baseline to first negative peak), and sensory nerve action potential (SNAP) amplitude (first positive to first negative peak), the latency difference between $\mathrm{H}$-reflex and $\mathrm{M}$-response $(\mathrm{H}-\mathrm{M}$ interval). The variables were considered abnormal when they exceeded the limits of normality at 2 SD level. These were: (1) tibial nerve CV $40 \mathrm{~m} / \mathrm{s}$, DML 5,9 ms, CMAP 2,0 $\mathrm{mV}$; (2) sural nerve CV $39 \mathrm{~m} / \mathrm{s}$, SNAP 2,5 $\mu \mathrm{V}$; (3) ulnar nerve (motor) CV $47 \mathrm{~m} / \mathrm{s}$, DML 3,7 ms, CMAP 1,7 mV; (4) ulnar nerve (sensory) wrist-fifth finger CV $44 \mathrm{~m} / \mathrm{s}$, SNAP 5,6 $\mu \mathrm{V}$; (5) ulnar nerve sensory elbowwrist $\mathrm{CV} 54 \mathrm{~m} / \mathrm{s}$. For the $\mathrm{H}-\mathrm{M}$ interval the normal limits of Visser et $a l^{23}$ were taken. Criteria for demyelination were: (1) CMAP area on proximal stimulation less than $50 \%$ of the CMAP area on distal stimulation, indicating a conduction block ${ }^{24}$; (2) elbow to wrist CV less than $40 \mathrm{~m} / \mathrm{s}$ in the ulnar nerve, or less than $30 \mathrm{~m} / \mathrm{s}$ in the tibial or sural nerve; (3) ulnar DML longer than $7 \mathrm{~ms}$ or tibial DML longer than $10 \mathrm{~ms}^{25}$ Axonal degeneration was diagnosed if one of the following was found: (1) spontaneous EMG activity such as fibrillation potentials, positive sharp waves or complex repetitive discharges on concentric needle examination; (2) reduced amplitude of CMAP or SNAP in the absence of conduction block.

\section{Results}

Seventy five patients were studied (46 men and 29 women). The mean age at the onset of symptoms was 56.5 years (SD 6.4). The mean time from onset of symptoms to entry into the study was $6 \cdot 3$ years (SD $4 \cdot 3$ ). On clinical grounds 44 patients (21 men, 23 women) had a sensorimotor, 29 patients (23 men, 6 women) a pure sensory, and two men a pure motor polyneuropathy. In motor neuropathies the symptoms and signs were purely motor except for a diminished vibration sense 
in the big toe which was not regarded as evidence for sensory involvement.

\section{SYMPTOMS}

In all patients the symptoms had developed in the course of 6 to 12 months. All symptoms had become symmetrical within the first 3 months. In all but one patient the symptoms started distally in the legs. In one patient the symptoms started with tingling in the hands; after 6 months she also complained about tingling in her feet.

In the sensorimotor neuropathy the most common presenting symptoms were tingling in the sole of the foot (14 patients), a heavy, tired feeling or weakness in the feet (10 patients), and sensations of numbness in the feet (nine patients). Other initial complaints were band-like sensations around the ankles, a feeling of stiffness in the calf and the feeling of walking on cotton wool. In the sensory neuropathy the presenting symptoms were paresthesias in the feet (nine patients), numbness of the feet (12 patients), and a burning pain in the soles of the feet (seven patients) (table 1). The two patients with a clinically pure motor neuropathy developed a bilateral footdrop within a couple of months as initial symptom.

In 35 of the 75 patients the symptoms spread to the hands in an average course of 5 years. In the other 40 patients the symptoms were limited to the legs, from the knees downward. In none of the patients the arms were solely affected.

In the sensorimotor polyneuropathy cramps in the calf muscles were frequently noted, especially after walking (table 1). In due course almost all patients experienced muscle weakness in the legs causing a disturbance of gait due to a bilateral foot drop. The patients with sensory polyneuropathy frequently complained about numbness of the fingers, causing difficulty in opening or closing small buttons and in dropping small objects out of the hands. In four patients the symptoms also spread proximally in the legs, mainly causing burning or electrical sensations. These painful sensations were most disabling, disturbing sleep and causing restlessness. During the daytime these painful sensations were less pronounced. Patients with a sensory polyneuropathy also often had to look where they were walking to prevent them from falling

Table 1 Symptoms and clinical course in patients with chronic idiopathic polyneuropathy

\begin{tabular}{|c|c|c|}
\hline & $\begin{array}{l}\text { Sensorimotor } P N \\
n=44(\%)\end{array}$ & $\begin{array}{l}\text { Sensory } P N \\
n=29(\%)\end{array}$ \\
\hline \multicolumn{3}{|l|}{ Symptoms: } \\
\hline Pain & $12(27)$ & $18(62)$ \\
\hline Tingling & $30(68)$ & $29(100)$ \\
\hline Numbness & $29(66)$ & $25(86)$ \\
\hline Band-like sensations & $8(18)$ & $8(28)$ \\
\hline Cotton wool & $16(36)$ & $19(66)$ \\
\hline Stiffness & $20(46)$ & $6(21)$ \\
\hline Muscle cramps & $27(61)$ & $6(21)$ \\
\hline Weakness & $36(82)$ & $0(0)$ \\
\hline \multicolumn{3}{|l|}{ Clinical course } \\
\hline $\begin{array}{l}\text { Slowly progressive, stable } \\
\text { Slowly progressive }\end{array}$ & $\begin{array}{l}12(27)^{\star} \\
32(73)^{\star}\end{array}$ & $\begin{aligned} 21(72)^{\star} & (28)^{\star}\end{aligned}$ \\
\hline
\end{tabular}

and usually walked with a broad based gait. When standing still they could only maintain their balance by leaning against a wall or other solid object. Sometimes cramps in the calf muscles were noted, although no motor deficits were found on neurological examination. In the sensorimotor polyneuropathy none of the patients had autonomic symptoms, while two patients with a sensory polyneuropathy had symptoms of bladder dysfunction and impotence, as a possible manifestation of an autonomic neuropathy. None of the patients had cranial nerve involvement.

\section{CLINICAL COURSE}

In the years before entry into the study, the clinical course of the polyneuropathy showed two patterns. In 42 patients the clinical course was slowly progressive over the years, whereas in 33 patients the course was initially slowly progressive followed by a prolonged period of stable deficit. In the patients with a sensory polyneuropathy the clinical course more often had a tendency to stabilise (table 1). No relation could be found between the duration of the illness and the occurrence of stabilisation.

During a 6 month follow up period the sensory neuropathy patients tended to stabilise as assessed by our patient evaluation and the Rankin disability scores. Also no aetiological cause of the peripheral neuropathy was identified. Long term follow up is still in progress.

SIGNS

In all patients the dysfunction was most prominent in the legs.

In the sensorimotor polyneuropathy, the pinprick sense was diminished in a stockinglike distribution distal to the ankle in 40 patients, and distal to the wrist in six patients. Light touch sensation was diminished in the same patients and with the same distribution as the pinprick sense. In all patients the vibration sense was diminished in the legs, mostly not perceptible on the malleolus. Sixteen patients showed diminished vibration sense on the middle finger. The joint position sense was normal in the hands in all patients and absent on the big toe in four. Romberg's sign was abnormal in 18 patients. Diminished or absent deep tendon reflexes of the arms was only seen in combination with diminished or absent reflexes of the legs. In all patients Achilles' tendon reflexes were absent bilaterally. In 11 patients all reflexes were absent. There was wasting of the interosseus muscles of the hands in nine patients, although weakness was not a prominent feature. In the legs there was wasting of the extensor digitorum brevis muscle, and frequently of the peroneal and anterior tibial muscles. No wasting was seen in the proximal muscles of the arm and legs. Weakness (MRC grade 3 and 4) was most prominent in the peroneal muscle $(72.7 \%)$, and in the anterior tibial muscle $(61 \cdot 3 \%)$. No fasciculations or tremor was seen.

In the sensory polyneuropathy, the pinprick 
sense was diminished in a stocking-like distribution distal to the ankle in 24 patients and distal to the wrist in six patients. Light touch sensation was diminished in 29 patients in the legs and in six patients in the hands, with the same distribution as the pinprick sense. In all patients the vibration sense was diminished in the legs, usually below the knees. In 12 patients the vibration sense was diminished below the ulnar styloid process. In three patients the joint position sense was diminished on the middle finger and in 10 patients absent on the big toe. Romberg's sign was abnormal in 13 patients. The pattern of tendon reflex abnormalities was similar to that seen in the sensorimotor polyneuropathy, although complete absence of tendon reflexes was less frequent (five patients). No fasciculations or tremor were seen.

In the motor polyneuropathy, there was wasting of the interosseus, the extensor digitorum, the peroneal, the anterior tibial and the calf muscles. The power was diminished in the hands (MRC grade 4) and distally in the legs (MRC grade 2 and 3). In the proximal muscles there was no weakness.

\section{DISABILITY}

Fifty three patients were independent in their daily activities. Eight patients needed the use of a walking stick and 13 an ankle brace. Only one patient was wheelchair dependent due to a severe bilateral arthrosis of both knees, and bilateral weakness of ankle dorsiflexion. On the Rankin scale 39 patients had a score of 1,35 patients a score of 2 , and one patient a score of 3 .

\section{ELECTROPHYSIOLOGICAL ASSESSMENT}

Sixty four patients fulfilled the electrophysiological criteria of axonal sensory (reduced SNAP amplitude) and axonal motor (spontaneous EMG activity, reduced CMAP amplitude) neuropathy. Seven patients had an axonal sensory polyneuropathy. In two patients there was evidence of a demyelinating motor polyneuropathy as well as an axonal motor and sensory polyneuropathy. In the two patients with a demyelinating polyneuropathy the clinical course was slowly progressive over months, leading to a minor handicap only, with the age at onset being 58 and 64 years respectively. In none of the 75

Table 2 Electrophysiological findings in chronic idiopathic polyneuropathy

\begin{tabular}{|c|c|c|c|c|c|c|}
\hline \multirow{2}{*}{$\frac{\text { Needle examination }}{\text { Fibrillations/Pos spikes }}$} & \multicolumn{3}{|c|}{$\begin{array}{l}\text { Sensorimotor polyneuropathy } \\
n=40(\%)\end{array}$} & \multicolumn{3}{|c|}{$\begin{array}{l}\text { Sensory polyneuropathy } \\
n=20(\%)\end{array}$} \\
\hline & $26(65)$ & & & $4(20)$ & & \\
\hline \multirow{2}{*}{$\begin{array}{l}\text { Nerve conduction } \\
\text { studies }\end{array}$} & \multicolumn{2}{|c|}{$C M A P / S N A P$} & \multirow{2}{*}{$\begin{array}{l}C V \\
\text { decr }\end{array}$} & \multicolumn{2}{|c|}{$C M A P / S N A P$} & \multirow{2}{*}{$\begin{array}{l}C V \\
\text { decr }\end{array}$} \\
\hline & decrt & NO & & decr' & NO & \\
\hline $\begin{array}{l}\text { Ulnar nerve (motor) } \\
\text { Ulnar nerve (sensory) } \\
\text { Tibial nerve } \\
\text { Sural nerve }\end{array}$ & $\begin{array}{l}0 \\
12(30) \\
19(48) \\
5(13)\end{array}$ & $\begin{array}{l}0 \\
2(5) \\
5(13) \\
28(70)\end{array}$ & $\begin{array}{l}6(15) \\
2(5) \\
23(58)^{\star} \\
6(15)\end{array}$ & $\begin{array}{l}0 \\
6(30) \\
4(20) \\
2(10)\end{array}$ & $\begin{array}{l}0 \\
0 \\
0 \\
12(60)\end{array}$ & $\begin{array}{l}3(15) \\
6(30) \\
9(45) \\
2(10)\end{array}$ \\
\hline
\end{tabular}

*In two patients the $\mathrm{CV}$ of tibial nerve is $<30 \mathrm{~m} / \mathrm{s}$.

$\mathrm{NO}=$ not obtainable.

decr ${ }^{1}=$ CMAP/SNAP is decreased below normal values (see methods)

decr $^{2}=\mathrm{CV}$ is decreased below normal values but $\mathrm{CV}$ is faster than $40 \mathrm{~m} / \mathrm{s}$ of ulnar nerve, faster than $30 \mathrm{~m} / \mathrm{s}$ of the tibial and sural nerve (see Methods). patients was conduction block found. In two patients the polyneuropathy was unclassified (increased $\mathrm{H}-\mathrm{M}$ interval). Some patients refused repeated electromyographic evaluation. The results of 60 patients who fulfilled the entire standardised EMG protocol are presented in table 2.

\section{LABORATORY}

CSF was obtained in 73 patients. The mean protein was $0.43 \mathrm{~g} / 1$ (SD 0.16 ) (95\% confidence limits $0 \cdot 15-0.45)$. The two patients with electrophysiological evidence of demyelination had a normal CSF protein $(0.41$ and $0.44)$. Nerve biopsy was performed in 31 patients. No signs of demyelination, inflammation, vasculitis, ${ }^{20}$ or amyloidosis were found. All nerve biopsy specimens showed axonal degeneration. Sera from 70 patients were investigated for the presence of antibodies against MAG, GM1, and sulphatides; all were negative.

\section{Discussion}

Chronic idiopathic polyneuropathy presenting in middle or old age is a heterogeneous clinical syndrome. In the published reports only a few studies on neuropathies of unknown cause have been conducted. Most studies show the percentage in which the neuropathy remains idiopathic (table 3), although a few also mention aspects of the clinical picture of this group of neuropathies. None of these studies are strictly comparable as they use different exclusion criteria, are not all prospective in nature, and use different electromyographic criteria. The study by McLeod et $a l^{3}$ may be the best compared with the present study in this respect. In their review of 67 patients with an idiopathic polyneuropathy, McLeod et $a l^{3}$ found 43 mixed, 17 sensory and seven motor neuropathies. In almost all of their patients the polyneuropathy was axonal. They also found an overall predilection for men (3:1)(table 3).

In our patients the cause of the chronic neuropathy remained unknown even after extensive evaluation. By definition of its unknown cause it may be misleading to divide undiagnosed neuropathies into subsets. On clinical grounds, however, it appears that chronic idiopathic polyneuropathy can be divided into groups. Leaving the motor neuropathy out of scope, two groups remain which can be distinguished by means of their different clinical presentation: sensorimotor and sensory polyneuropathy. There is a tendency for the sensorimotor polyneuropathies to run a slowly progressive course, whilst the sensory polyneuropathies have an initially slowly progressive course, followed by a prolonged phase without progression (table 1). A clear difference is found in the sex distribution. The sensorimotor polyneuropathies are equally distributed among the sexes, whereas in sensory polyneuropathies there is a strong predilection for men $(4: 1)$. Contrary to these differences concerning the clinical course and sex distribution, both groups share an overall 
Table 3 Review of studies on neuropathies of unknown cause

\begin{tabular}{|c|c|c|c|c|c|c|c|}
\hline Reference & $\begin{array}{l}\text { Number } \\
\text { of } \\
\text { patients }\end{array}$ & $\begin{array}{l}\% \\
\text { unknown } \\
\text { cause }\end{array}$ & $\begin{array}{l}\text { Mean age } \\
\text { at } \\
\text { onset }\end{array}$ & $\begin{array}{l}\text { Neuropathy } \\
(\%) \\
\text { sm/sens/mot/oth }\end{array}$ & $\begin{array}{l}\text { Patients with } \\
\text { elevated CSF } \\
\text { protein (\%) }\end{array}$ & $\begin{array}{l}\text { Neurophysiological } \\
\text { investigation } \\
(\%)\end{array}$ & $\begin{array}{l}\text { Biopsy } \\
\text { (\%) } \\
\text { ax/dem/mix }\end{array}$ \\
\hline 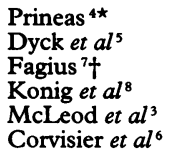 & $\begin{array}{r}278 \\
205 \\
91 \\
70 \\
519 \\
432\end{array}$ & $\begin{array}{l}36 \\
24 \\
74 \\
14 \\
13 \\
11\end{array}$ & $\begin{array}{l}40-50 \\
59 \\
72 \ddagger \\
51 \\
65\end{array}$ & $\begin{array}{l}84 / 6 / 10 / 0 \\
\overline{99} / 1 / 0 / 0 \\
42 / 30 / 0 / 28 \\
64 / 27 / 9 / 0 \\
66 / 0 / 0 / 34\end{array}$ & $\begin{array}{l}\frac{50}{7} \\
29 \\
14 \sqrt{55}\end{array}$ & $\begin{array}{l}\mathrm{CV} \downarrow 100 \\
-\quad \text { ax } 18 ; \text { dem } 15 ; \operatorname{mix} 67 \\
\text { CV } \downarrow 84 ; \text { denerv } 94 \\
\text { CV } \downarrow \text { mot; sens imp }\end{array}$ & $\begin{array}{l}- \\
- \\
\overline{100} \\
41 / 48 / 0\end{array}$ \\
\hline
\end{tabular}

sens = sensory; $\mathrm{sm}=$ sensorimotor; mot $=$ motor; oth $=$ other neuropathies (for example, asymmetric neuropathies, mononeuritis multiplex), CV $\downarrow$ = slowing conduction velocity; denerv = denervation; imp = impairment. $-=$ no data available.

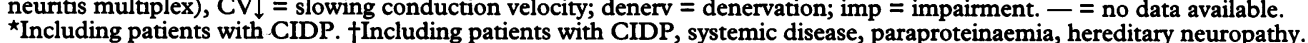
IIn four of the six patients with an elevated CSF protein $1>\mathrm{g} / \mathrm{l}$, a malignancy was found during follow up. $¥$ Inclusion criteria age over 60 .

benign course reflected by the minimal degree of disability found in our patients. The electrophysiological examination and nerve biopsy specimen show axonal degeneration in almost all our patients with chronic idiopathic polyneuropathy.

In only two patients electromyographic evidence of demyelination was found (table 2). The clinical course of these two patients was not consistent with a CIDP and their CSF protein was not elevated. In $95 \%$ of patients with a CIDP, the CSF protein is found to be higher than $0.45 \mathrm{~g} / 1 .{ }^{21}$ In addition, our patients showed distal weakness predominantly in the legs, while patients with a CIDP usually have more extensive weakness. ${ }^{26}$ Patients with a CSF protein in the range of $0.45-1.0 \mathrm{~g} / 1$ underwent a sural nerve biopsy. A nerve biopsy was not performed in all patients as the neuropathy was not sufficiently severe enough to warrant an invasive investigation which may produce persistent dysaesthesias. ${ }^{9}$ Theoretically speaking, some cases of inflammatory neuropathies and vasculitis could have been overlooked in our study, however, none of the laboratory findings or the clinical course gave any clues for an inflammatory or vasculitic cause of the polyneuropathy.

In the above analysis the two patients with a pure motor neuropathy were left out. The more progressive and disabling clinical course of these patients appears quite distinct from the sensorimotor and sensory neuropathies which show a more benign course. Because of these clinical differences we wonder whether these two patients with clinically a motor neuropathy and with electrophysiological evidence of an additional sensory neuropathy have a late onset HMSN 2. Patients with a slowly progressive predominantly motor axonal neuropathy, with onset in adult life, sometimes present as late onset HMSN $2 .{ }^{12}$

Could chronic sensory polyneuropathy be a chronic variant of acute sensory neuropathy? Windebank et $a l^{27}$ described patients with acute sensory neuropathy; the symptoms developed within a time course of seven days or less. In about half of the patients the symptoms started asymmetrically or in the upper arms. Approximately $50 \%$ of the patients developed facial symptoms in addition. This is in contrast with our patients with a more chronic course of sensory polyneuropathy in whom the symptoms started in the legs, which were always more affected than the arms. None had facial symptoms. Therefore, it is unlikely that chronic sensory neuropathy is a variant of the acute sensory neuropathy.

Basically a polyneuropathy can only be classified as idiopathic after exclusion of all known possible causes. Sometimes patients with a sensorimotor neuropathy appear to have a dominant or recessive hereditary form of HMSN 2, or alternatively represent cases of sporadic HMSN $2 .{ }^{28}$ In up to $15 \%$ of patients with a dominant form of HMSN 2 the onset of symptoms presents after the age of 50. In our study a detailed family history was negative and next of kin suspected of having a polyneuropathy did not have neurological abnormalities on examination. ${ }^{5}$ These results imply that the dominant form of HMSN 2 is an unlikely diagnosis for most of our patients. Moreover, HMSN 2 usually does not present with tingling or numbness in the feet, as did most patients in our group. ${ }^{12}$

Another intriguing question is whether ageing of the nervous system plays an important role. In that case we would expect an increase of the number of affected patients with an increase with age which is not the case. The mean age of onset of the idiopathic neuropathies is in middle age (table 3 ).$^{4-7}$

We have to consider the possibility of toxic neuropathy and chronic alcoholism. Environmental influences may be responsible for chronic idiopathic polyneuropathy. However, in our study the presence of, or contact with, any known toxic agent was a reason for exclusion and none of the patients used drugs or were on a diet. Considering chronic alcoholism, our inquiries on this topic have been extensive (including hetero-anamnestic data, data of the patient's general practitioner). McLeod et $\mathrm{al}^{3}$ revealed initially unsuspected causes in their long term follow up study. At present, our short time follow up study gave no clue for any toxic neuropathy or alcoholism.

Malignancy is an unlikely explanation for causing the neuropathy. Almost all our patients had a polyneuropathy for many years (mean 5 years) before entry into the study without any evidence of a malignant disease. ${ }^{29} 30$

Finally, Sjögren's disease and the possibility of another immunological aetiology of chronic idiopathic polyneuropathy have to be considered. Polyneuropathy may be the initial manifestation of Sjögren's syndrome. ${ }^{31}$ The mean interval between the onset of polyneu- 
ropathy and the occurrence of Sjögren's syndrome in a large series was 24 months. ${ }^{31}$ In the present study, however, the mean follow up period was about 5 years, signs of xerophthalmia and xerostomia were absent, and serological tests for Sjögren's syndrome were negative. Dalakas found in his study in patients with chronic idiopathic ataxic neuropathies that nine of the 15 patients had a monoclonal or polyclonal serum gammopathy. ${ }^{32}$ In our study the presence of serum monoclonal proteins was a reason for exclusion. Patients with primarily axonal neuropathies rarely have antibodies against MAG. ${ }^{33}$ Since the majority of our patients have an axonal polyneuropathy, it is not surprising, that antibodies against MAG were absent. Recently, Pestronk et al ${ }^{17}$ described eight patients with an idiopathic sensory neuropathy who had antibodies against sulphatides; these antibodies were absent in sera from our patients with a sensory neuropathy.

In conclusion, chronic idiopathic polyneuropathy presenting in middle or old age is a heterogeneous clinical syndrome. It is interesting that all patients have an axonal polyneuropathy and only minimal disability even after a long duration of symptoms. A follow up of at least 6 months did not provide an answer concerning the aetiology of these peripheral neuropathies. Long term follow up is still in progress.

The authors are very grateful to Dr EMG Joosten, Professor The authors are very grateful to Dr EMG Joosten, Professor $M$ de Visser, Professor HFM Busch, Dr EACM Sanders, and
Dr JAL Vanneste for referring their patients to us and to Dr JAL Vanneste for referring their patients to us and to
Professor $\mathrm{N}$ Latov for measuring the antibodies against Professor N Latov for measuring the antibodies against
sulphatides. This study was supported by a grant from the sulphatides. This study
Prinses Beatrix Fonds.

1 Matthews WB. Cryptogenic polyneuritis. Proc $R$ Soc Med 1952;45:667-9.

2 Rose FC. Discussion on neuropathies. Proc $R$ Soc Med 1960;53:51-3.

3 McLeod JG, Tuck RR, Pollard JD, Cameron J, Walsh JC. Chronic polyneuropathy of undetermined cause. f Neurol Neurosurg Psychiatry 1984;47:530-5.

4 Prineas JW. Polyneuropathies of undetermined cause. Acta Neurol Scand 1970;44(suppl): 1-72.

5 Dyck PJ, Oviatt KF, Lambert EH. Intensive evaluation of referred unclassified neuropathies yields improved diagnosis. Ann Neurol 1981;10:222-6.

6 Corvisier N, Vallat JM, Hugon J, Lubeau M, Dumas M. Les polyneuropathies de cause indeterminée. Rev Neurol 1987;143:279-83.

7 Fagius J. Chronic cryptogenic polyneuropathy. Acta Neurol Scand 1983;67:173-80.

8 Konig F, Neundorfer B, Kompf D. Polyneuropathien im hoheren Lebensalter. Deutsch Med Wschr 1984;109: 735-7.

9 Hughes RAC. Chronic polyneuropathy of undetermined cause. In: Matthews WB, ed. Handbook of clinical neurology neuropathies. Amsterdam: Elsevier, 1987;7:529-41.

10 Dyck PJ, Lais AC, Ohta M, et al. Chronic inflammatory polyradiculoneuropathy. Mayo Clin Proc 1975;50: polyradicul

11 Gosselin SG, Kyle RA, Dyck PJ. Neuropathy associated with monoclonal gammopathies of undetermined significance. Ann Neurol 1991;30:54-61.

12 Harding A, Thomas PK. The clinical features of hereditary motor and sensory neuropathy types 1 and 2 . Brain 1980;103:259-80.

13 Jacobs JM, Love S. Qualitative and quantitative morphology of human sural nerve at different ages. Brain 1985;108:897-924.

14 Van Swieten JC, Koudstaal PJ, Visser MC, et al. Interobserver agreement for assessment of handicap in Interobserver agreement for assessment

15 Latov N, Hays AP, Sherman WH. Peripheral neuropathy and anti-MAG antibodies. CRC Crit Rev Neurobiol and anti-MAG

16 Van den Berg LH, Marrink J, de Jager AEJ, et al. AntiGM1 antibodies in patients with Guillain Barre syndrome. I Neurol Neurosurg Psychiatry 1992;55:8-11.

17 Pestronk A, Li F, Griffin J, et al. Polyneuropathy syndromes associated with serum antibodies to sulfatide and myelin-associated glycoprotein. Neurology 1991;41: 357-62.

18 Thomas PK. How useful is nerve biopsy [abstract]? F Neurol Sci 1990;98(suppl): 115 .

19 Notermans NC, Wokke JHJ, Jennekens FGI. Clinical work-up of the patient with a polyneuropathy. In: de Jong JMBV ed. Handbook of clinical neurology. Hereditary neuropathies and spinocerebellar atrophies. Amsterdam: neuropathies and spinocere

20 Dyck PJ, Benstead TJ, Conn DL, et al. Non systemic vasculitis neuropathy. Brain 1987;110:843-54.

21 Barohn RJ, Kissel JT, Warmolts JR, Mendell JR. Chronic inflammatory demyelinating polyradiculoneuropathy, clinical characteristics, course and recommendations for diagnostic criteria. Arch Neurol 1989;14:878-84.

22 Oh SJ. Clinical electromyography: nerve conduction studies. Baltimore: University Park Press, 1984.

23 Visser SL, Zonneveldt A, de Rijke W, et al. Normal Hoffmann reflex latencies ( $H-M$ interval) in relation to age and body length. Clin Neurol Neurosurg 1983; 518:86-91.

24 Rhee EK, England JD, Sumner AJ. A computer simulation of conduction block: effects produced by actual block versus interphase cancellation. Ann Neurol 1990 28:146-56.

25 McLeod JG, Prineas JW, Walsh JC. The relationship of conduction velocity to pathology in peripheral nerves. In: Desmedt E, ed. New developments in electromyography and clinical neurophysiology 1973;2:248-58.

26 McCombe PA, Pollard JD, McLeod JG. Chronic inflammatory demyelinating polyradiculoneuropathy. A clinical and electrophysiological study of 92 cases. Brain 1987;110:1617-30.

27 Windebank AJ, Blexrud MD, Dyck PJ, Daube JR, Karnes $J$. The syndrome of acute sensory neuropathy: Clinical features and electrophysiologic and pathologic changes. Neurology 1990;40:584-91.

28 Harding A, Thomas PK. Autosomal recessive forms of hereditary motor and sensory neuropathy. $\mathcal{f}$ Neurol Neurosurg Psychiatry 1980;43:669-78.

29 Hawley RJ, Cohen MH, Saini N, Armbrustmacher VW. The carconomatous neuromyopathy of oat cell lung cancer. Ann Neurol 1980;7:65-72.

30 Horwich MS, Cho L, Porro RS, Posner JB. Subacute sensory neuropathy: a remote effect of carcinoma. Ann Neurol 1977;2:7-19.

31 Mellgren SI, Conn DL, Stevens JC, Dyck PJ. Peripheral neuropathy in primary Sjögrens syndrome. Neurology 1989;39:390-4.

32 Dalakas MC. Chronic idiopathic ataxic neuropathy. Ann Neurol 1986;19:545-54.

33 Nobile-Orazio E, Francomano E, Daverio R, et al. Antimyelin-associated glycoprotein IgM antibody titers in neuropathy associated with macroglobulinemia. Ann Neurol 1989;26:543-50. 